\title{
Modified Cement System: Durability and Aesthetics
}

\author{
Mohamed, J. S. Z. ${ }^{1}$, Mohamed, S.N. ${ }^{2}$
}

\begin{abstract}
Concrete deterioration is one of the most concern matters in construction world. The concrete deterioration such as efflorescence should not be ignored. The efflorescence is a deposit salts, usually white, formed on a surface of concrete. The efflorescence is not a major problem that leads to structural defects but it can build unattractiveness to the structure such as brick wall and concrete mortar. The way to prevent the efflorescence occurrence is by studying the results of testing such as absorption and efflorescence itself to reduce the efflorescence. The non-modified cement system can reduce the efflorescence but cannot avoid it because of the reaction of cement hydration itself. This study is to prove that by using a modified cement system such as Pulverized Fly Ash (PFA) and Polymers (water based latex grade 29Y46), the efflorescence of the mortar can be prevented. The results from this study proved the modified mortar which is a sample with PFA and Polymers has higher strength, durability, and less efflorescence compared with the non-modified cement system.
\end{abstract}

Keywords: Concrete, Efflorescence, Durability, Pulverized Fly Ash, Polymers

I. INTRODUCTION

$\mathrm{O}$ $\mathrm{NE}$ of the main characteristics influencing the durability of concrete is its permeability. The ingress of water, oxygen, carbon dioxide, chloride and others is the most durability problem in the concrete that can be attributed to the changes in the concrete. Volume changes in the concrete can be caused by many factors such as hydration process, pozzolonic action, sulphate attack, carbonation, moisture movement, and others. A crack can decrease the durability of the concrete that occurs by interactions involving the materials of concrete and its surrounding environment

Colours changes of concrete can arise due to a well known yet not well understood phenomenon called efflorescence. Efflorescence occurs when water percolates through poorly compacted concrete or through cracks when evaporation can take place at the surface of the concrete. It will form white deposits which can decrease the aesthetic value of the concrete. Efflorescence, which used to be ignored due to its negligible structural effect, is now viewed as a major problem in colored concrete products. To date there are no economical and effective methods to guarantee the prevention of efflorescence [11].

\section{EXPERIMENTAL PROGRAM}

The preparation of specimens varies with concrete mixes according to the predefined proportions. Concrete samples are tested through a series of test methods. The arrangement of the experimental program can be summarized in the flow chart as shown in figure 1.

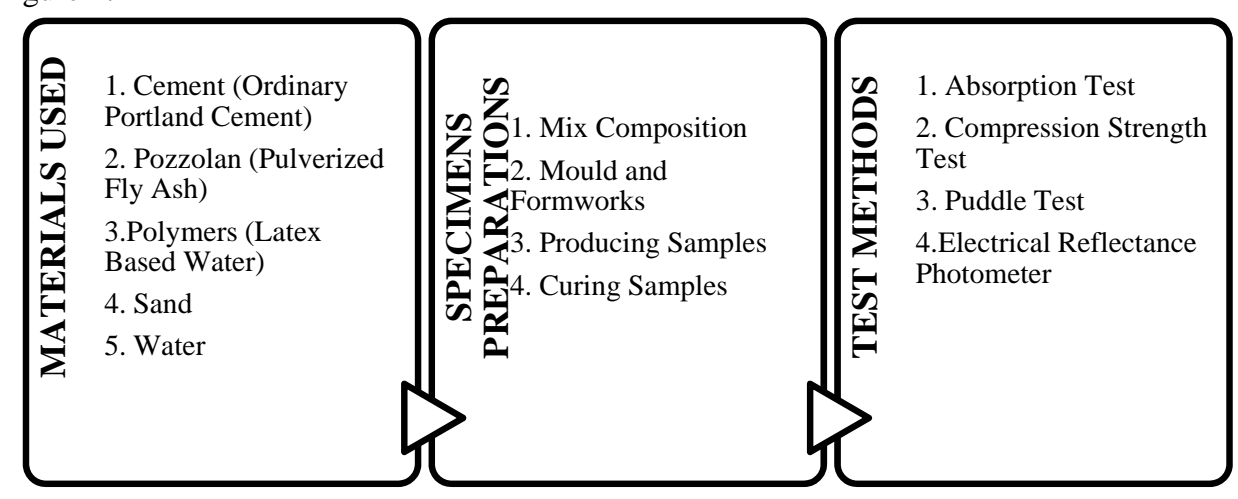

Figure 1: Flow Chart of the Experimental Program 


\section{RESULTS AND ANALYSIS}

\section{i) Absorption Test}

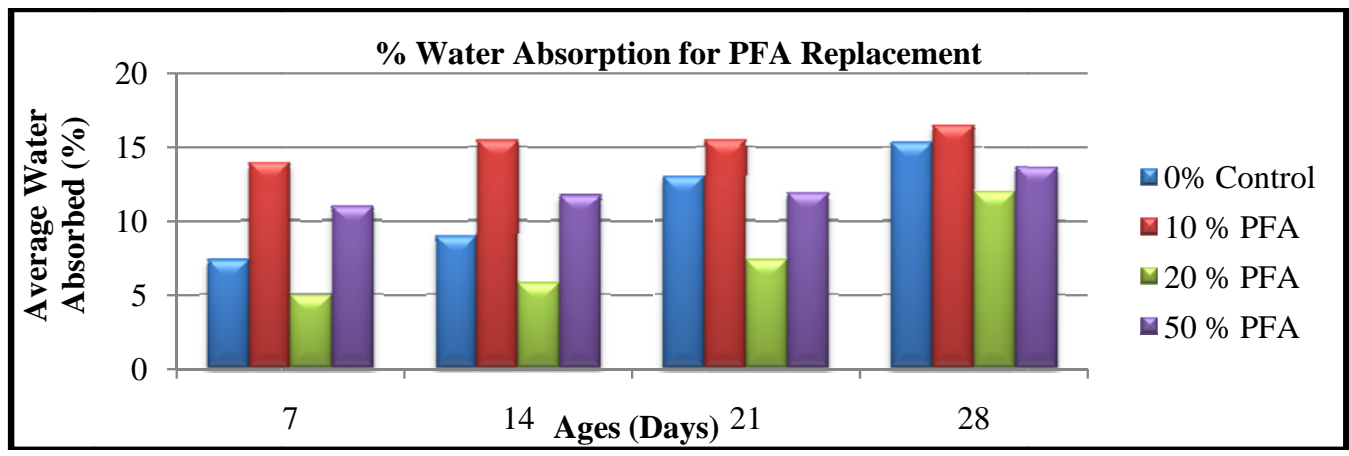

Figure 2: Water Absorption between 0\%, 10\%, 20\% and 50\% PFA

Referring to the figure 2, it shows that the highest water absorbtion is $10 \%$ PFA replacement followed by $50 \%$ PFA replacement. While, the $20 \%$ PFA replacement is the lowers percentage of water absorption.

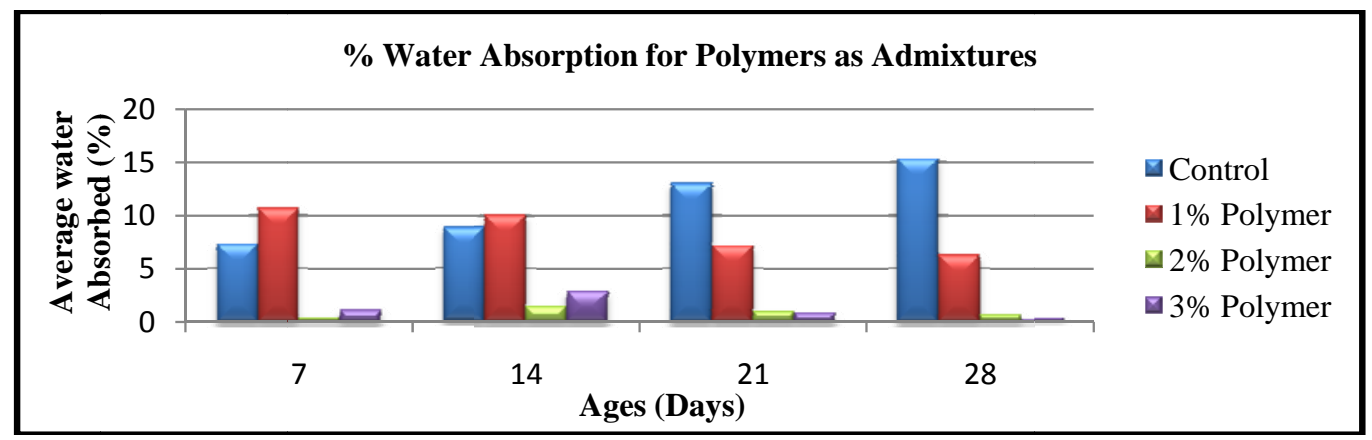

Figure 3: Water Absorption between 0\%, 1\%, 2\% and 3\% Polymers

Figure 3 shows that the percentage of sample mixes with Polymer and non modified mortar. For the non- modified mortar water absorption increased constantly with curing time. While the sample with addition of Polymer water absorption starts to drop off constantly on days 14. It shows that the more polymers added into the mixtures, the lesser water can be absorbed into the sample. From the result, it can be concluded that the sample with PFA has higher percentage water absorption compared with the sample with Polymers. When the air content is high in PFA sample, more amount of water can be absorbed. While, the polymer modified mortar have a structure in which the larger pores can be filled by polymers. These features are reflected in reduced water absorption. For that reason, it can be concluded that polymerization of monomers by additives and thermal activation, the hardening of latex takes place by drying or loss of water.

\section{ii) Compression Strength Test}

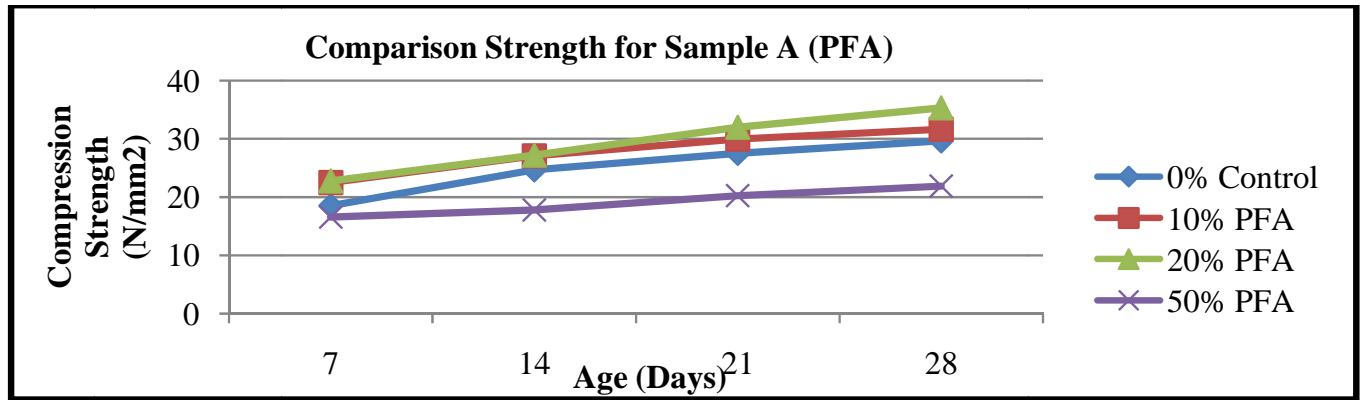

Figure 4: Comparison strength between $0 \%, 10 \%, 20 \%$ and $50 \%$ PFA 
Figure 4 shows the relationship between the compressive strength of PFA materials and 100\% Portland cement. The 20\% replacement of PFA is sufficient to reduce the calcium hydroxide to the minimum level in the sample and it the highest compressive strength in 28 days compared to $10 \%$, 50\% PFA and non-modified mortar. The 20\% replacement of PFA is suitable using in construction which can reduce the cost in non-modified cement system.

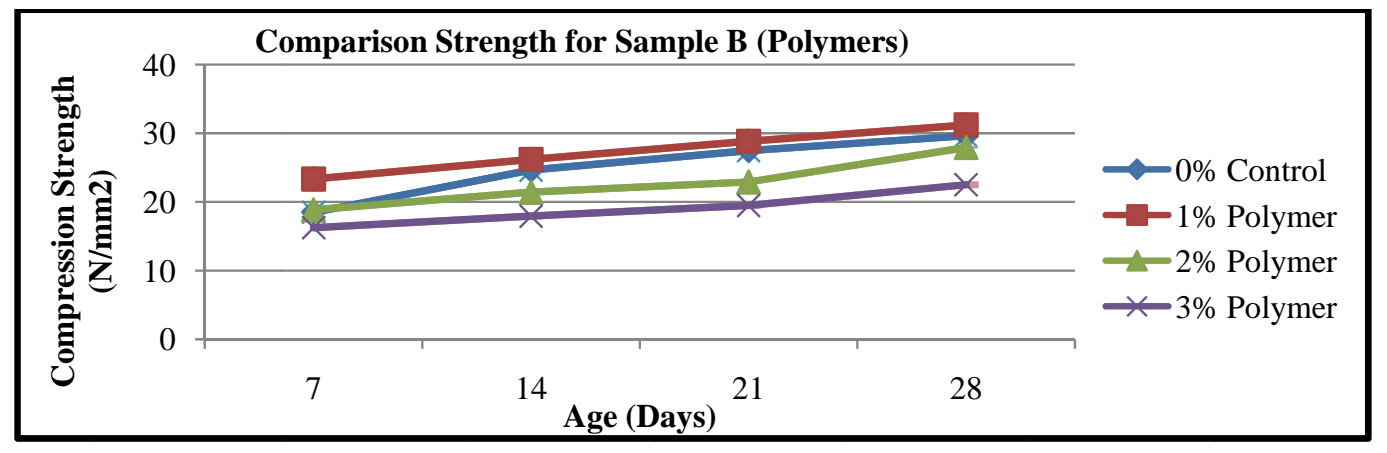

Figure 5: Comparison strength between 1\%, 2\% and 3\% Polymer

From figure 5, it can be concluded that additives with $1 \%$ of polymers developed a higher strength than those with $2 \%$, $3 \%$ and $0 \%$ of modified mortar. The molecules of polymer linked together with water and cement to attain a higher strength. However, only concrete with additives 1\% polymers exhibits higher strength than the control sample at all ages.

\section{iii) Puddle Test \& Electrical Reflectance Photometer}

The puddle tests and electrical reflectance photometer have been done to measure the efflorescence and aesthetic of the concrete cubes. The measure of efflorescence is the difference color between the modified cement system and nonmodified cement system. The humidity during the testing is around $86 \%$ and the temperature is around $27.5^{\circ} \mathrm{C}$ during curing and absorption testing. High relative humidity around $80 \%$ to $95 \%$ provides a good protection against efflorescence after one or more days. Low humidity relatively takes a very long time to eliminate the risk of efflorescence. Low curing temperature can reduces the formation of protection against efflorescence. Puddle test is carried out by using mixtures which is absorbing more water than other sample. For PFA sample, the percentage that absorbs more water is $10 \%$ replacement while for Polymer sample, the percentage that absorbs more water is $1 \%$ addition of Polymers.

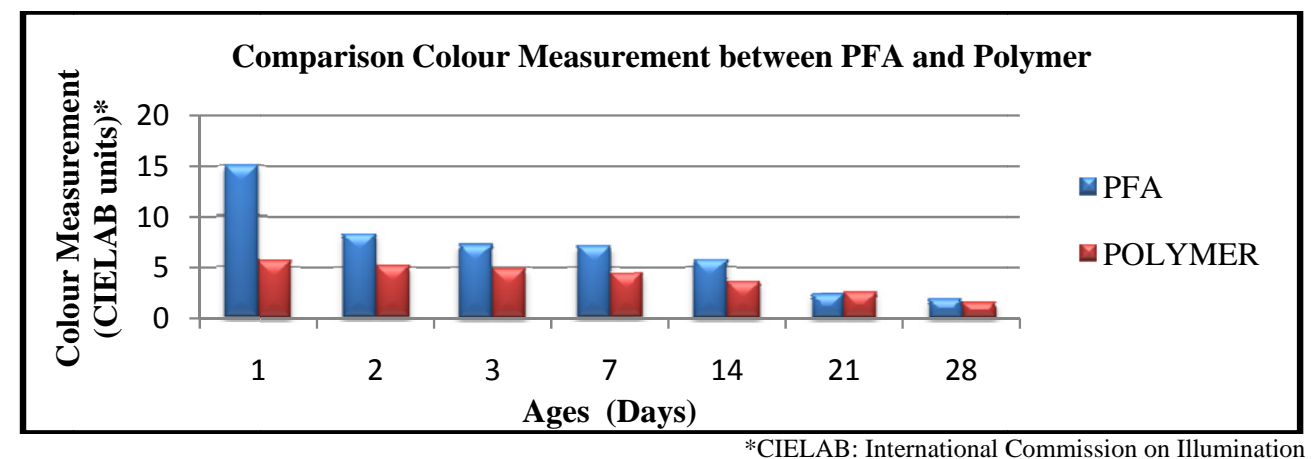

Figure 5: Comparison color measurement between PFA and Polymer

Figure 5 shows that DE (total colour difference); for sample PFA on days 1 is the highest or darker than others DE. The colour measurement of both samples increase constantly with ageing. But the sample PFA shows the higher of colour measurement compared to the sample with Polymers. The water absorption of the cube is the main reason for the colour measurement of change in both samples. Previous subtopic shows that the addition of PFA leads to absorption more water; whilst the addition of polymer gives less water absorption. For that reason, the colour measurement or efflorescence properties may be affected also.

It can be concluded that, the mixtures with modified cement system is better than non-modified cement system while the comparison between PFA and Polymers shows that the colour measurement of sample with Polymers achieved less values or less efflorescence. The admixtures with more additives of polymers are not sufficient to develop adequate strength but reduce the build up of efflorescence. 


\section{CONCLUSIONS:}

As the conclusions, the concrete additives and concrete replacement with PFA can reduce the calcium efflorescence. It has been proved that replacement with fly ash and adding polymer to concrete can prevent the efflorescence. For determination of efflorescence, the mixtures with modified cement system are better than non-modified cement system. The comparison between PFA and Polymer shows that the colour measurement of sample with Polymers achieved the lesser value. The admixtures with more additives of polymers are not sufficient to develop adequate strength but less in build up of efflorescence. The high relative humidity around $80 \%$ to $95 \%$ give a good protection against efflorescence. Low curing temperature can reduce the formation of protection against efflorescence also. The strength compressive test proved that PFA with $20 \%$ replacement is sufficient to reduce the calcium hydroxide to the minimum level. While, the additives with $1 \%$ of polymers developed a higher strength at all ages. As a final conclusion, the additive with $1 \%$ Polymers in mixtures can reduce efflorescence; absorb more water and give more strength to the concrete.

\section{Acknowledgment}

The authors would like to express sincere gratitude to everyone who involved directly and indirectly to make this study a success.

\section{REFERENCES}

[1] A. M. Neville ( 1996 ). Properties of Concrete. $4^{\text {th }}$ and Final ed. Harlow, England: Longman

[2] Y.Ohama, ( 1994 ). Polymers in Concrete. $1^{\text {st }}$ ed.CRC Press Inc. United States of America

[3] M. S. J. Gani ( 1997 ). Cement and Concrete. $1^{\text {st }}$ ed. 2-6 Boundary Row, London SE1 8HN, UK: Chapman \& Hall

[4] Michael S. Mamlouk and John P. Zaniewski. (2006). Materials for Civil and Construction Engineers. $2^{\text {nd }}$ ed. New Jersey : Prentice Hall

[5] T.C. Powers, "Structure and physical properties of hardened Portland cement paste", Journal of American Ceramic Society, 1985, 41, 1-6

[6] Mehta, P. K. "Pozzolanic and cementitious by-products as mineral admixtures for concrete - a critical review”; ACI SP-79, 1983, pp. 1-46. Editor: V.M. Malhotra.

[7] G. D. Taylor. ( 2002 ). Materials in Construction. Principles, Practice and Performance. $2^{\text {nd }}$ ed. Harlow, England: Longman

[8] V. M. Malhotra and P. Kumar Mehta. Pozzolanic and Cementitious Materials. Advances in Concrete Technology. Volume 1. London and New York: Taylor \& Francis Group

[9] Malhotra, V.M., Carette, G.G and Aitcin, P.C. "Mechanical properties of Portland cement concrete incorporating blast furnace slag and condensed silica fume"; Proceedings, RILEM/ACI Symposiums on Technology of Concrete When Pozzolans, Slag and Chemical Admixtures are Used, Monterrey, Mexico, pp. 395-414. 1985.

[10] Jackson Neil, and Dhir Ravindra K. ( 1996 ). Civil Engineering Materials. $5^{\text {th }}$ ed. Palgrave : New York

[11]P.Kresse, "Coloured concrete and its enemy: efflorescence, “Chemistry and Industry, pp. 93-95,1989,"

[12] Pulverized Fuel Ash, http://www.logicsphere.com/products/firstmix/hlp/html/pfa7rn2.htm and http://www.flyash.com. Accessed on September 20, 2008

[13] Mehta, P. K. "Influence of fly ash characteristics on the strength of Portland cement-fly ash mixtures"; Cement and Concrete Research, V. 15, 1985, pp. 669-674.

[14] Nawy, Edward G ( 2000 ). Fundamentals of High - Performance Concrete. $2^{\text {nd }}$ ed. Canada. John Wiley and Sons, Inc 